\title{
Cyclotron production and radiochemical purification of terbium-155 for SPECT imaging
}

\author{
C. Favaretto ${ }^{1,4}$, Z. Talip 1 , F. Borgna', P. V. Grundler ${ }^{1}$, G. Dellepiane ${ }^{2}$, A. Sommerhalder ${ }^{1}$, H. Zhang ${ }^{3}$, R. Schibli ${ }^{1,4}$, \\ S. Braccini ${ }^{2}$, C. Müller ${ }^{1}$ and N. P. van der Meulen ${ }^{1,5^{*}}$ (1)
}

\author{
*Correspondence: \\ nick.vandermeulen@psi.ch \\ ${ }^{5}$ Laboratory \\ of Radiochemistry, \\ Paul Scherrer Institute, \\ 5232 Villigen-PSI, Switzerland \\ Full list of author information \\ is available at the end of the \\ article
}

\begin{abstract}
Background: Terbium-155 [ $\left.T_{1 / 2}=5.32 \mathrm{~d}, \mathrm{EY}=87 \mathrm{keV}(32 \%) 105 \mathrm{keV}(25 \%)\right]$ is an interesting radionuclide suitable for single photon emission computed tomography (SPECT) imaging with potential application in the diagnosis of oncological disease. It shows similar decay characteristics to the clinically established indium-111 and would be a useful substitute for the diagnosis and prospective dosimetry with biomolecules that are afterwards labeled with therapeutic radiolanthanides and pseudo-radiolanthanides, such as lutetium-177 and yttrium-90. Moreover, terbium-155 could form part of the perfect "matched pair" with the therapeutic radionuclide terbium-161, making the concept of true radiotheragnostics a reality. The aim of this study was the investigation of the production of terbium-155 via the ${ }^{155} \mathrm{Gd}(p, n)^{155} \mathrm{~Tb}$ and ${ }^{156} \mathrm{Gd}(\mathrm{p}, 2 \mathrm{2n})^{155} \mathrm{~Tb}$ nuclear reactions and its subsequent purification, in order to obtain a final product in quantity and quality sufficient for preclinical application. The ${ }^{156} \mathrm{Gd}(\mathrm{p}, 2 \mathrm{n}){ }^{155} \mathrm{~Tb}$ nuclear reaction was performed with $72 \mathrm{MeV}$ protons (degraded to $\sim 23 \mathrm{MeV}$ ), while the ${ }^{155} \mathrm{Gd}(\mathrm{p}, \mathrm{n})^{155} \mathrm{~Tb}$ reaction was degraded further to $\sim 10 \mathrm{MeV}$, as well as performed at an $18 \mathrm{MeV}$ medical cyclotron, to demonstrate its feasibility of production.
\end{abstract}

Result: The ${ }^{156} \mathrm{Gd}(\mathrm{p}, 2 \mathrm{n})^{155} \mathrm{~Tb}$ nuclear reaction demonstrated higher production yields of up to $1.7 \mathrm{GBq}$, however, lower radionuclidic purity when compared to the final product $(\sim 200 \mathrm{MBq})$ of the ${ }^{155} \mathrm{Gd}(\mathrm{p}, \mathrm{n})^{155} \mathrm{~Tb}$ nuclear reaction. In particular, other radioisotopes of terbium were produced as side products. The radiochemical purification of terbium-155 from the target material was developed to provide up to $1.0 \mathrm{GBq}$ product in a small volume $(\sim 1 \mathrm{~mL} 0.05 \mathrm{M} \mathrm{HCl})$, suitable for radiolabeling purposes. The high chemical purity of terbium-155 was proven by radiolabeling experiments at molar activities up to $100 \mathrm{MBq} / \mathrm{nmol}$. SPECT/CT experiments were performed in tumorbearing mice using [ $\left.{ }^{155} \mathrm{~Tb}\right]$ Tb-DOTATOC.

Conclusion: This study demonstrated two possible production routes for high activities of terbium-155 using a cyclotron, indicating that the radionuclide is more accessible than the exclusive mass-separated method previously demonstrated. The developed radiochemical purification of terbium-155 from the target material yielded $\left.{ }^{155} \mathrm{~Tb}\right] \mathrm{TbCl}_{3}$ in high chemical purity. As a result, initial cell uptake investigations, as well as SPECT/CT in vivo studies with [ $\left.{ }^{155} \mathrm{~Tb}\right] \mathrm{Tb}$-DOTATOC, were successfully performed, indicating that the chemical separation produced a product with suitable quality for preclinical studies. 
Keywords: Terbium-155, Matched pairs, Radiolanthanides, Theragnostics, Radionuclide production, Proton irradiation, Cyclotron, Radiochemical purification, SPECT/CT imaging

\section{Background}

In recent years, nuclear medicine emerged as an increasingly important area in the diagnosis and treatment of both oncological and non-oncological diseases (Weber et al. 2020). In particular, in the field of diagnosis, Single Photon Emission Computed Tomography (SPECT) has been used for many years as a non-invasive imaging technique. (Mariani et al. 2010). The combination of SPECT with CT increased interest in the technique for its accuracy in the depiction of the localization of disease (Buck et al. 2008). This application, however, demands radionuclides with the appropriate decay properties. To date, SPECT/CT had applications and expansion mainly thanks to the use of technetium-99 m $\left[E \gamma=141 \mathrm{keV}(89 \%), \mathrm{T}_{1 / 2}=6.01 \mathrm{~h}\right.$, (Browne and Tuli 2017)] which is the most often used radionuclide in clinical diagnostic nuclear medicine (Lee 2019).

Our group is investigating the emerging role of novel promising radionuclides for theragnostics (Domnanich et al. 2016; Gracheva et al. 2019; van der Meulen et al. 2015, 2020b; Müller et al. 2012). Among these radionuclides, terbium-155 is of high interest because it is a radiolanthanide that emits $\gamma$-rays of energies suitable for SPECT $[\mathrm{E} \gamma=87 \mathrm{keV}$ (32\%) $105 \mathrm{keV}$ (25\%)] (Nica 2019). Terbium-155 decays with a half-life of 5.32 days, which can allow the study of pre-therapeutic dosimetry and tumor visualization at later time points after administration (Müller et al. 2014a). The mentioned decay properties make terbium-155 a valid alternative to indium-111 $[\mathrm{E} \gamma=245 \mathrm{keV}$ (94\%) $171 \mathrm{keV}$ (91\%), $\mathrm{T}_{1 / 2}=2.80 \mathrm{~d}$, (Blachot 2009)], which has been employed for the diagnosis and pretreatment dosimetry with biomolecules that are afterwards labeled with radiolanthanides and pseudo-radiolanthanides, such as lutetium-177 and yttrium-90, commonly used for $\beta^{-}$-particle therapy (Witzig 2001). It is worth mentioning, however, that the small differences in the coordination chemistry between indium and lanthanides may lead to differences in the biodistribution of the correspondingly-radiolabeled compound (Camera et al. 1994). Therefore, indium-111 is not a perfect diagnostic match to therapeutic radiolanthanides. The radiolanthanide terbium-155 would enable using chemically identical or nearly identical radiopharmaceuticals for imaging and therapy and, thus, allow its application for prospective dosimetry (Borgna et al. 2021). Furthermore, the optimal practice would be the combined use of the same molecular targeting vectors, labeled either with a diagnostic or therapeutic radionuclide of the same element. This approach is known as radiotheragnostics and would allow the most accurate proceeding for the diagnosis and dosimetry on the patient before performing the treatment (Rösch et al. 2017). In this regard, terbium-155 may be used as a precise diagnostic match for the $\alpha$-emitter terbium-149 (Müller et al. 2012; Umbricht et al. 2019) or, in a greater degree, for the $\beta^{-}$-particle-emitting terbium-161 $\left(\mathrm{T}_{1 / 2}=6.96\right.$ days, (Durán et al. 2020)), which has recently been produced in high quality and tested in preclinical and clinical studies (Baum et al. 2021; Favaretto et al. 2021; Gracheva et al. 2019; Müller et al. 2019). Moreover, the long half-life of terbium-155 would be favorable for tumor visualization at late time points after injection which may be interesting in particular 
with longer-circulating biomolecules. Therefore, the availability of large quantities of terbium-155 with adequate purity would be of particular value for clinical application.

To date, previous studies reported terbium- 155 production via high-energy protoninduced spallation of a tantalum target followed by ionization and mass separation (Fiaccabrino et al. 2021; Müller et al. 2012, 2014a; Webster et al. 2019). The current limitation of this method is the overall separation efficiency due to the currently poor efficiency of surface ionization, thus, the production of terbium-155 in large quantities via this production route appears not to be a viable option. Other than the spallation reactions, the production of terbium-155 is also possible by means of two proton-induced direct reactions: ${ }^{155} \mathrm{Gd}(\mathrm{p}, \mathrm{n}){ }^{155} \mathrm{~Tb}$ and ${ }^{156} \mathrm{Gd}(\mathrm{p}, 2 \mathrm{n}){ }^{155} \mathrm{~Tb}$ (Fig. 1) (Dmitriev et al. 1989). The accumulation of terbium radionuclide impurities is sensibly reduced, thanks to the use of highly-enriched gadolinium oxide as target material that results in the production of high activities of terbium-155 with minimal radionuclidic contaminants (Vermeulen et al. 2012). Cross section measurements using these target materials were performed and will be reported elsewhere (Dellepiane et al. 2022). The ${ }^{156} \mathrm{Gd}(\mathrm{p}, 2 \mathrm{n}){ }^{155} \mathrm{~Tb}$ nuclear reaction suggests high production yields, however, it requires the use of higher-energy cyclotrons. The ${ }^{155} \mathrm{Gd}(\mathrm{p}, \mathrm{n})^{155} \mathrm{~Tb}$ reaction can be performed with medical cyclotrons (typical proton energy, $18 \mathrm{MeV}$ ), allowing the production of terbium-155 with such a device.

The aim of the present study was to explore, for the first time, the production of high terbium-155 activities via proton irradiation of highly-enriched gadolinium-155 and gadolinium-156 oxide targets at Paul Scherrer Institute (PSI), Switzerland, and its subsequent radiochemical separation from target material and impurities. Terbium-155 labeling experiments were performed as part of the quality control, and the utility of terbium-155 for SPECT imaging demonstrated.

\section{Methods}

\section{Terbium-155 production}

Target preparation

Enriched gadolinium oxide $\left(\left[{ }^{155} \mathrm{Gd}\right] \mathrm{Gd}_{2} \mathrm{O}_{3} 91.9 \%\right.$ enrichment or $\left[{ }^{156} \mathrm{Gd}\right] \mathrm{Gd}_{2} \mathrm{O}_{3} 93.3 \%$ enrichment, Isoflex, USA) was used as target material for the production of terbium-155 via the ${ }^{155} \mathrm{Gd}(\mathrm{p}, \mathrm{n}){ }^{155} \mathrm{~Tb}$ and ${ }^{156} \mathrm{Gd}(\mathrm{p}, 2 \mathrm{n}){ }^{155} \mathrm{~Tb}$ nuclear reactions, respectively. The elemental composition of the target materials in question is provided in Additional file 1

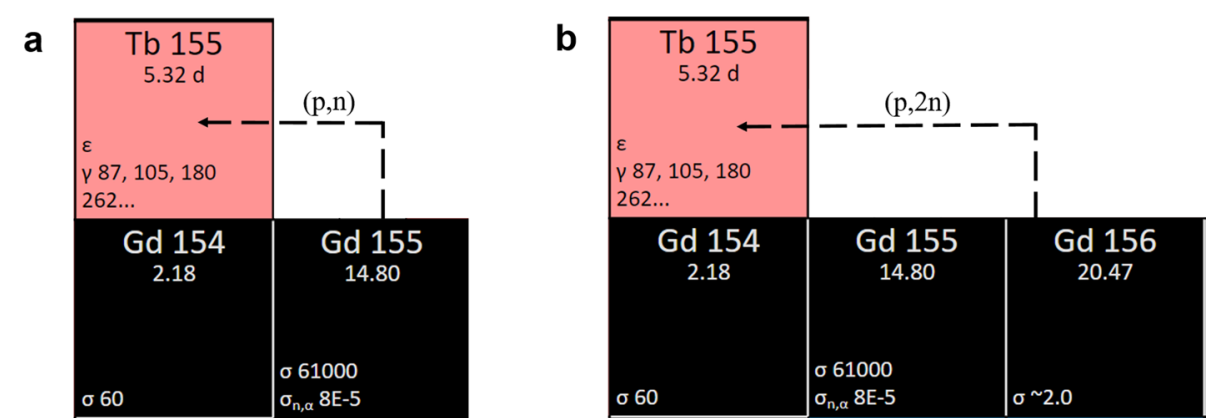

Fig. 1 Nuclear reactions for the production of terbium-155 via proton irradiation of enriched $\left[{ }^{155} \mathrm{Gd}\right] \mathrm{Gd}_{2} \mathrm{O}_{3}$ and $\left[{ }^{156} \mathrm{Gd}\right] \mathrm{Gd}_{2} \mathrm{O}_{3}$ targets. ${ }^{155} \mathrm{Gd}(\mathrm{p}, \mathrm{n}){ }^{155} \mathrm{~Tb}(\mathbf{a})$ and ${ }^{156} \mathrm{Gd}(\mathrm{p}, 2 \mathrm{n}){ }^{155} \mathrm{~Tb}(\mathbf{b})$. 
(Additional file 1: Tables S1 and S2). Approximately $40 \mathrm{mg}$ of material was pressed into $\sim 6 \mathrm{~mm}$ diameter disc-shaped pellets, $0.3 \mathrm{~mm}$ thick, by applying an axial pressure of 2 tons for $5 \mathrm{~s}$.

\section{Target irradiations using PSI's Injector 2 cyclotron}

The pellets produced by compression of the enriched material were encapsulated in aluminum (99.5\% pure) capsules specifically designed in-house for PSI's IP2 irradiation station (Grundler et al. 2020; van der Meulen et al. 2020a) (Fig. 2).

The gadolinium targets were irradiated, using the $72 \mathrm{MeV}$ proton beam from the Injector 2 separated sector cyclotron. The beam current was set to $50 \mu \mathrm{A}$. Niobium discs ( $3.4 \mathrm{~mm}$ and $2.4 \mathrm{~mm}$, respectively) were used as degraders to decrease the proton energy from $72 \mathrm{MeV}$ to the desired energy windows (Grundler et al. 2020; van der Meulen et al. 2015, 2020a). The thicknesses of the degraders were calculated using SRIM2013 (Ziegler et al. 2010). The beam energy was set to $\sim 10.3 \mathrm{MeV}$ for the (p,n) reaction and $\sim 22.8 \mathrm{MeV}$ for the (p,2n) reaction according to the cross-section measurements previously performed (Dellepiane et al. 2022; Dmitriev et al. 1989; Vermeulen et al. 2012). The irradiations were performed for up to $8 \mathrm{~h}$ (Additional file 1: Table S3). The energy of the protons exiting the target was calculated using SRIM for the case of $40 \mathrm{mg}$ targets. It was found to be $(20.7 \pm 1.5) \mathrm{MeV}$ and $(6.0 \pm 3.4) \mathrm{MeV}$, for entry energies of $22.8 \mathrm{MeV}$ and $10.3 \mathrm{MeV}$, respectively.

\section{Target irradiations at the Bern medical cyclotron}

Two irradiations were performed with the medical cyclotron (IBA Cyclone $\mathrm{HC} 18 \mathrm{MeV}$ ) in operation at the Bern University Hospital (Inselspital), to demonstrate the feasibility to produce terbium-155 via the ${ }^{155} \mathrm{Gd}(\mathrm{p}, \mathrm{n}){ }^{155} \mathrm{~Tb}$ nuclear reaction with such a machine. This facility features two bunkers with independent access, the former for the cyclotron and the latter for a $6 \mathrm{~m}$ long Beam Transfer Line (BTL) for multidisciplinary research activities (Braccini 2013). The cyclotron is equipped with an IBA Nirta Solid Target Station (STS), a mechanical transfer system (named Hyperloop) to load the STS from outside the cyclotron bunker and a pneumatic solid target transfer system (STTS) by Tema Sinergie to deliver the irradiated target either to a hot-cell or to a receiving station located in the BTL bunker (Braccini et al. 2020). To assess the produced activity, a

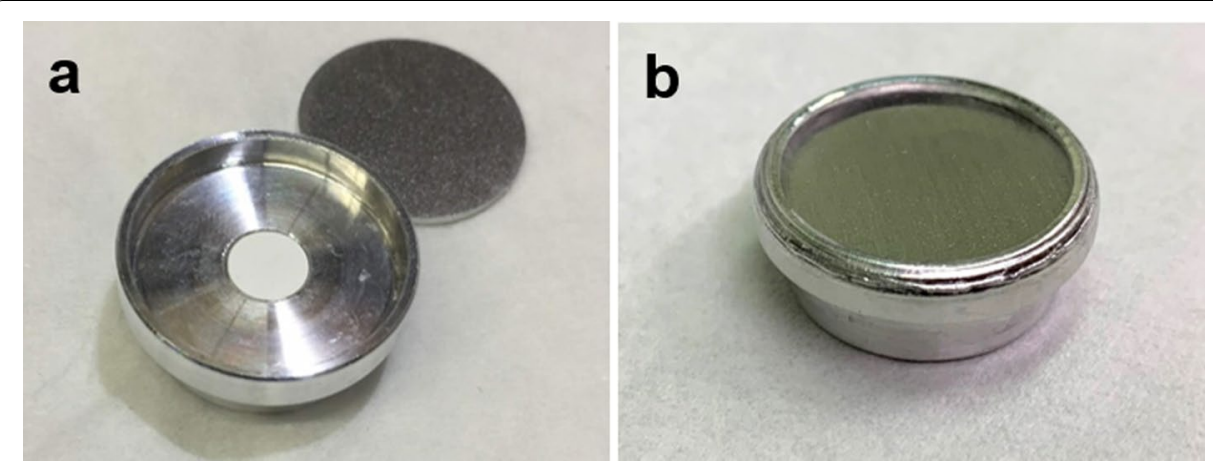

Fig. 2 Open (a) target capsule containing a $6 \mathrm{~mm}$ gadolinium oxide target nestled in an indentation, and (b) sealed target capsule 
semiconductor detector system based on a $3 \mathrm{~cm}^{3} \mathrm{CdZnTe}$ (CZT) crystal was installed in the receiving station (Dellepiane et al. 2021). The $\left[{ }^{155} \mathrm{Gd}\right] \mathrm{Gd}_{2} \mathrm{O}_{3}$ targets for the irradiation at the medical cyclotron were prepared by compression of enriched material, as described above. The disc-shaped pellets were inserted in a specific capsule-named "coin"-composed by two halves kept together by permanent magnets, as shown in Fig. 3. This capsule was developed by the Laboratory of High Energy Physics (LHEP) at the University of Bern, Switzerland, and was previously successfully used to produce scandium-44 (van der Meulen et al. 2020b).

The two irradiations of the $\left[{ }^{155} \mathrm{Gd}\right] \mathrm{Gd}_{2} \mathrm{O}_{3}$ targets were performed at $2.4 \mu \mathrm{A}$ and 0.7 $\mu \mathrm{A}$ beam intensity with $10.9 \mathrm{MeV}$ and $10.5 \mathrm{MeV}$ proton energy, respectively (Additional file 1: Table S4). The entry and exit energies were tuned by adjusting the thickness of the covering lid of the coin. On the basis of the measured production cross sections, the energies were chosen to optimize the production yield, while minimizing the impurities (Dellepiane et al. 2022). The irradiations were conducted for 70 and $40 \mathrm{~min}$, respectively.

\section{Radiochemical separation process}

The terbium-155 separation from the gadolinium target material and impurities was developed by means of bench experiments using three types of resin (described below) with the use of $\gamma$-emitting radioactive tracers (gadolinium-153 and terbium-160) and ICP-standards of the elements of interest (Additional file 1). After loading the columns, the lanthanides were eluted with suitable eluents (see below), and the fractions obtained from the elutions measured by means of $\gamma$-ray spectrometry or ICP-OES (Agilent 5110 ICP-OES, USA). With the data gathered from these experiments, the elution profiles of terbium and gadolinium from three different types of resins were established (Additional file 1: Figs. S1-S5).

Based on the bench experiments results, a chemical separation system was designed, built, and introduced into a hot cell, such that high activities of the radionuclide could be manipulated with reduced radiation-dose exposure to the operator. Selected irradiated targets (excluding production runs 1 and 4, that were performed only for production yield data) were processed using this setup. After the irradiation,

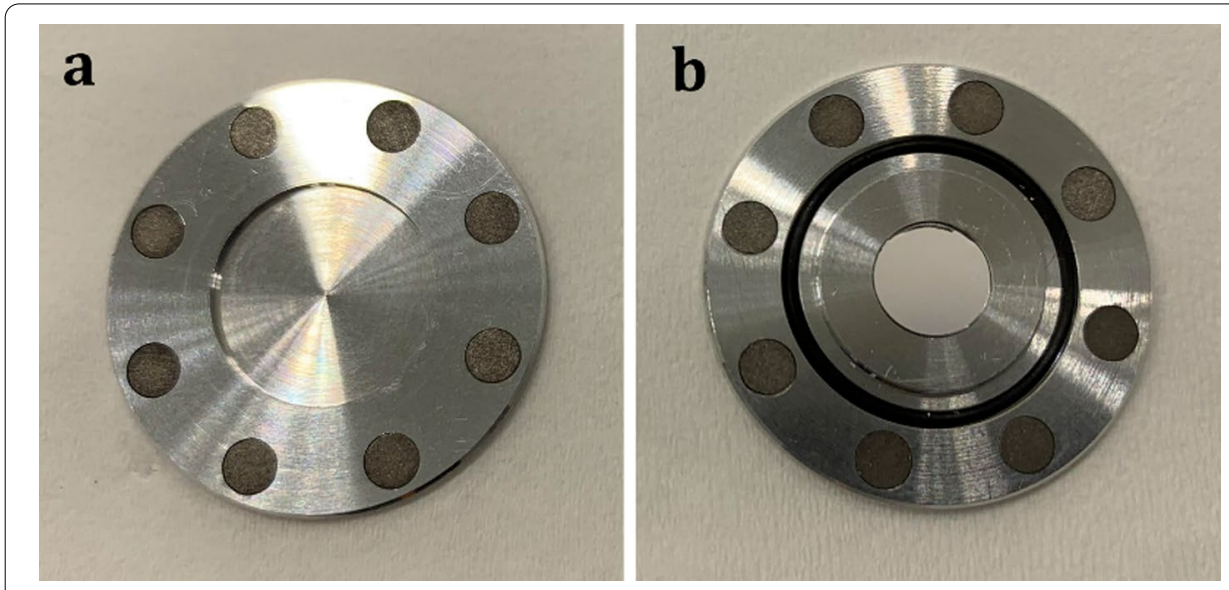

Fig. 3 Covering lid (a) and back part (b) of the "coin", containing a $6 \mathrm{~mm}$ gadolinium oxide target. 
the targets were removed from their aluminum capsules in a hot cell, placed into a Reacti-Vial $^{\mathrm{TM}}$ (Thermo Fisher Scientific, USA) and transferred to the separation panel. The target was dissolved in $5 \mathrm{~mL} 7.0 \mathrm{M} \mathrm{HNO}_{3}$ (Suprapur, Merck, Germany) by heating for $30 \mathrm{~min}$ at $100{ }^{\circ} \mathrm{C}$. The solution was loaded onto a chromatographic column $(10 \mathrm{~mm} \times 100 \mathrm{~mm})$ filled with $N, N, N, N$ '-tetra-n-octyldiglycolamide extraction resin (DGA Normal resin, Triskem International, France; particle size 50-100 $\mu \mathrm{m}$, column volume: $8.5 \mathrm{~mL}$ ). Terbium-155 elution from the DGA column was performed with the use of $0.05 \mathrm{M} \mathrm{HCl}$ (Suprapur, Merck, Germany) as eluent $(0.75 \mathrm{~mL}$ / min flow rate). While the first $15 \mathrm{~mL}$ of elution were discarded, the following $25 \mathrm{~mL}$ were loaded onto a column containing Sykam macroporous cation exchange resin (Sykam Chromatographie Vertriebs $\mathrm{GmbH}$, Germany; particle size $12-22 \mu \mathrm{m}, \mathrm{NH}_{4}{ }^{+}$ form, column volume: $19.8 \mathrm{~mL}$ ) followed by $60 \mathrm{~mL}$ Milli-Q water. The terbium-155 separation from the target material was performed on the Sykam column with the use of $100 \mathrm{~mL} 0.13 \mathrm{M}(\mathrm{pH} 4.5) \alpha$-hydroxy-isobutyric acid ( $\alpha$-HIBA, Sigma-Aldrich $\mathrm{GmbH}$, Germany) as eluent $(0.6 \mathrm{~mL} / \mathrm{min}$ flow rate). The eluted fraction containing terbium-155 ( $25 \mathrm{~mL} 0.13 \mathrm{M} \alpha$-HIBA) was loaded onto the last column of the separation panel, prepared using $\sim 0.08 \mathrm{~mL}$ of bis(2,4,4-trimethyl-1-pentyl)phosphinic acid extraction resin (LN3, Triskem International, France; particle size 50-100 $\mu \mathrm{m}$ ) slurried in a $1 \mathrm{~mL}$ column. The final purification was performed by rinsing the LN3 resin with $10 \mathrm{~mL}$ Milli-Q water followed by $14 \mathrm{~mL} 0.01 \mathrm{M} \mathrm{HCl}$ (Suprapur, Merck $\mathrm{GmbH}$, Germany) at $1 \mathrm{~mL} / \mathrm{min}$. Finally, terbium-155 was eluted in a small volume $(\sim 1 \mathrm{~mL} 0.05 \mathrm{M} \mathrm{HCl})$ at a flow rate of $0.1 \mathrm{~mL} / \mathrm{min}$ in the form of $\left[{ }^{155} \mathrm{~Tb}\right] \mathrm{TbCl}_{3}$. During the entire process, the movement of terbium-155 activity along the column was monitored by means of pin diodes, which acted as detectors. The $\mathrm{pH}$ of the final product was determined using $\mathrm{pH}$ indicator strips. The target material separated from terbium-155 in each purification process could be recovered and recycled for reuse in future irradiations and productions (Additional file 1).

\section{Production yield, separation yield and radionuclidic purity}

The terbium-155 activities were determined before and after separation by $\gamma$-ray spectrometry using a high-purity germanium (HPGe) detector (Canberra, France), in combination with the Inter-Winner software package (version 7.1, Itech Instruments, France). The efficiency calibration was performed using an Eppendorf vial filled with a europium-152 solution $(89.51 \mathrm{kBq} \pm 0.71 \%$, reference date 20.02 .2017$)$ and placed at $1 \mathrm{~m}$ from the detector. A $5 \mu \mathrm{L}$ aliquot of the final product $\left(\left[{ }^{155} \mathrm{~Tb}\right]\right.$ $\mathrm{TbCl}_{3}$ ) was introduced in an Eppendorf vial and measured with uncertainty $\leq 5 \%$ at $1 \mathrm{~m}$ from the detector. Moreover, a small aliquot of the solution obtained from the target dissolution ( $5 \mathrm{~mL} \mathrm{7.0} \mathrm{M} \mathrm{HNO}_{3}$ ) was also measured with the same method. As a result, it was possible to calculate the production and separation yields, by decay correction and sample extrapolation, together with the activity obtained at the end of bombardment (EOB), and at the end of separation (EOS), respectively. The radionuclidic purity at EOS was assessed using the same method. 


\section{Radiolabeling yield}

After every separation process, the radiolabeling yield of the terbium-155 product was assessed to indirectly evaluate the chemical purity of the product and to ensure the capability of the radionuclide to radiolabel biomolecules at high molar activities required for (pre)clinical use. Terbium-155 ( 100 MBq) was added to a reaction mixture consisting of $0.05 \mathrm{M} \mathrm{HCl}$ and $0.5 \mathrm{M}$ sodium acetate with a final $\mathrm{pH}$ of $\sim 4.5$. DOTATOC $(1 \mathrm{mM})$ was added to obtain molar activities up to $100 \mathrm{MBq} / \mathrm{nmol}$. The reaction mixture was incubated at $95^{\circ} \mathrm{C}$ for $10 \mathrm{~min}$ (Müller et al. 2014b). Quality control was performed to determine the radiolabeled fractions of DOTATOC, as previously reported, by means of high-performance liquid chromatography (HPLC, Merck Hitachi, LaChrom) (Additional file 1) (Gracheva et al. 2019).

The radiolabeled samples with low radiolabeling yields were further analyzed by means of liquid chromatography-mass spectrometry-electrospray ionization (LCMS-ESI, Waters LCT Premier mass spectrometer) to identify the present metals (impurities) labeled to the peptide (Additional file 1).

\section{Preclinical studies}

Cell internalization and uptake of the ${ }^{155} \mathrm{~Tb}$-labeled somatostatin (SST) analogue DOTATOC were determined in somatostatin receptor (SSTR)-positive AR42J cells, according to a previously-published procedure (Additional file 1) (Borgna et al. 2021).

Animal studies were ethically approved by the responsible Committee of Animal Experimentation and permitted by the responsible cantonal authorities (license No. 75721) (Additional file 1). Five-week-old female, CD-1 nude mice (Charles River Laboratories, Germany) were subcutaneously inoculated with AR42J tumor cells $\left(5 \times 10^{6}\right.$ cells in $100 \mu \mathrm{L}$ PBS) as previously reported (Borgna et al. 2021). The SPECT/CT study was performed 10-14 days after tumor cell inoculation when the tumor size reached a volume of $\sim 250 \mathrm{~mm}^{3}$.

\section{SPECT/CT imaging studies}

A small-animal, 4-head multiplexing, multipinhole camera (NanoSPECT/CT; Mediso Medical Imaging Systems, Budapest, Hungary) was employed for SPECT/CT imaging studies, as previously reported (Additional file 1) (Borgna et al. 2021). In brief, the SPECT scans were acquired using Nucline software (version 1.02, Mediso Ltd., Budapest, Hungary) using energy windows set at $46.0 \mathrm{keV}( \pm 8.5 \%), 86.0 \mathrm{keV}( \pm 8.5 \%)$ and $105.0 \mathrm{keV}( \pm 10 \%)$. The real-time CT reconstruction used a cone-beam filtered backprojection. SPECT data were reconstructed iteratively with HiSPECT software (version 1.4.3049, Scivis GmbH, Göttingen, Germany) using standard settings. SPECT and CT data were automatically co-registered because both modalities shared the same axis of rotation. The fused datasets were processed using VivoQuant (version 3.5, inviCRO Imaging Services and Software, Boston USA). A Gaussian post-reconstruction filter $(\mathrm{FWHM}=1.0 \mathrm{~mm})$ was applied. 


\section{Derenzo phantom}

A Derenzo phantom with a diameter of $19.5 \mathrm{~mm}$, a height of $15.0 \mathrm{~mm}$ and with hole diameters ranging from 0.8 to $1.3 \mathrm{~mm}$ in $0.1-\mathrm{mm}$ steps, was filled with approximately $10 \mathrm{MBq}\left[{ }^{155} \mathrm{~Tb}\right] \mathrm{TbCl}_{3}$ solution in a total volume of $900 \mu \mathrm{L}$ containing $20 \%$ ethanol, to allow the complete filling of the capillaries (Bunka et al. 2016). Fifteenminute SPECT/CT scans were performed with $240 \mathrm{~s}$ time-per-view and processed as described in the previous section.

\section{In vivo studies}

$\left[{ }^{155} \mathrm{~Tb}\right] \mathrm{Tb}-\mathrm{DOTATOC}$, prepared as described above for quality control, was diluted in 0.05\% bovine serum albumin in PBS and intravenously injected in one AR42J-tumorbearing mouse $(\sim 10 \mathrm{MBq}, \sim 1 \mathrm{nmol})$. Scans were acquired 1,4 and $24 \mathrm{~h}$ after the injection and, during the scans, the mouse was anesthetized by inhalation of an isoflurane-oxygen mixture. Time-per-view of the scans was set to $30 \mathrm{~s}$, resulting in a scan time of about $20 \mathrm{~min}$.

\section{Results}

\section{Terbium-155 production}

\section{Production yields at PSI's Injector 2 cyclotron}

In agreement with the experimental cross section measurements (Dellepiane et al. 2022; Dmitriev et al. 1989), the (p,2n) reaction yielded higher activities compared to the $(\mathrm{p}, \mathrm{n})$ reaction. In particular, with $8 \mathrm{~h}$ irradiation of a $\left[{ }^{155} \mathrm{Gd}\right] \mathrm{Gd}_{2} \mathrm{O}_{3}$ target, $200 \mathrm{MBq}$ terbium-155 was produced, while the same irradiation time on $\left[{ }^{156} \mathrm{Gd}\right] \mathrm{Gd}_{2} \mathrm{O}_{3}$ targets yielded activities up to $1.7 \mathrm{GBq}$ (Table 1, Additional file 1: Table S3).

\section{Production yields at the Bern medical cyclotron}

The irradiations performed at the Bern medical cyclotron yielded $7.7 \pm 0.6 \mathrm{MBq}$ and $1.6 \pm 0.1 \mathrm{MBq}$ of terbium-155, according to the irradiation conditions reported in Table 1 and Additional file 1: Table S4. The obtained activities were measured first with the CZT detector right after the irradiation and with an HPGe detector several days after the EOB. A good agreement was found between the two measurements and with the calculation of the produced activities based on the measured cross sections (Dellepiane et al. 2022).

Table 1 Terbium-155 activities produced via ${ }^{155} \mathrm{Gd}(p, n){ }^{155} \mathrm{~Tb}$ and ${ }^{156} \mathrm{Gd}(p, 2 n)^{155} \mathrm{~Tb}$ nuclear reactions at PSI's IP 2 irradiation station and Bern medical cyclotron

\begin{tabular}{|c|c|c|c|c|}
\hline Nuclear reaction & Facility & Target mass (mg) & $\begin{array}{l}\text { Beam entry } \\
\text { energy (MeV) }\end{array}$ & $\begin{array}{l}{\left[{ }^{155} \mathrm{~Tb}\right] \mathrm{Tb}} \\
\mathrm{EOB}[\mathrm{MBq} / \\
(\mu \mathrm{Ah})]\end{array}$ \\
\hline${ }^{155} \mathrm{Gd}(p, n)^{155} \mathrm{~Tb}$ & $\begin{array}{l}\text { Bern Inselspital medi- } \\
\text { cal cyclotron }\end{array}$ & 38.0 & $\sim 10.7$ & $3.09 \pm 0.48$ \\
\hline${ }^{155} \mathrm{Gd}(p, n)^{155} \mathrm{~Tb}$ & PSI injector 2 & $39.7 \pm 1.2$ & $\sim 10.3$ & $0.42 \pm 0.26$ \\
\hline${ }^{156} \mathrm{Gd}(p, 2 n)^{155} \mathrm{~Tb}$ & PSI injector 2 & $39.5 \pm 0.8$ & $\sim 22.8$ & $3.28 \pm 0.65$ \\
\hline
\end{tabular}



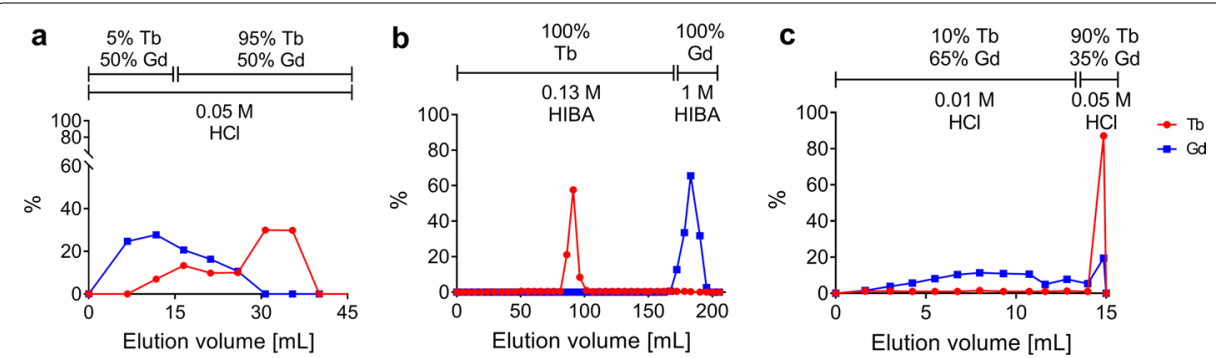

Fig. 4 Representative elution profiles of terbium and gadolinium from DGA column using $0.05 \mathrm{M} \mathrm{HCl}$ (a), from Sykam column using $0.13 \mathrm{M}$ and $1 \mathrm{M} \mathrm{a-HIBA}(\mathbf{b})$ and from LN3 column using $0.01 \mathrm{M} \mathrm{HCl}$ and 0.05 $\mathrm{M} \mathrm{HCl}(\mathbf{c})$. In this set of experiments, the columns were loaded with lanthanide metal tracers, which were subsequently eluted with the eluents mentioned. The sample aliquots were measured by means of ICP-OES.

\section{Radiochemical purification process}

With the data gathered in bench experiments with stable isotopes, the elution profiles of terbium and gadolinium were established for the three columns proposed for the purification process (Fig. 4). The elution profile experiments performed with the DGA column showed an advantageous initial separation between terbium and gadolinium (Fig. 4a). In particular, $~ 50 \%$ of gadolinium and only $~ 5 \%$ of terbium were eluted with the first $15 \mathrm{~mL}$ of eluent while, with the following $25 \mathrm{~mL}$, the remaining 95\% of terbium and $\sim 50 \%$ of gadolinium could be removed from the column, resulting in a gadolinium/terbium separation factor of $2.00 \pm 0.07 \%$. Loading only $50 \%$ of the target material onto the Sykam column increased the resin purification performances tremendously (Additional file 1: Fig. S3) and resulted in two highly resolute peaks in the Sykam elution profile (Fig. 4b). With the experiments performed on the LN3 column (Additional file 1: Fig. S4 and S5), it was feasible to obtain a further separation between terbium and gadolinium (separation factor from $\sim 4.5$ to $\sim 2.6$, depending on flow rate) with a rinse step performed with $0.01 \mathrm{M} \mathrm{HCl}$ before the final elution step carried out with the higher concentrated acid (0.05 M HCl) (Fig. 4c).

A chemical separation system for the separation of terbium-155 from proton-irradiated enriched gadolinium oxide targets, and potential impurities, was designed and built based on the bench experiments (Fig. 5). After the irradiation, selected targets were dissolved and successfully processed through the three columns mentioned above and, finally, terbium-155 was eluted in $1.0 \mathrm{~mL} 0.05 \mathrm{M} \mathrm{HCl}(\mathrm{pH} 1-2)$. A maximum of $7 \mathrm{~h}$ was needed to complete the radiochemical purification, thus, the process could be performed in one day.

\section{Separation yield and radionuclidic purity}

The final product $\left(\left[{ }^{155} \mathrm{~Tb}\right] \mathrm{TbCl}_{3}\right)$ in $1 \mathrm{~mL} 0.05 \mathrm{M} \mathrm{HCl}$ had an activity concentration of $0.02-1.0 \mathrm{MBq} / \mu \mathrm{L}$. When performing the $500 \mu \mathrm{L}$-fractionated collection, however, it was determined that the first $500 \mu \mathrm{L}$ fraction contained about $70-80 \%$ of the total activity.

The separation yields, calculated considering the initial terbium-155 activity of the targets after irradiation (EOB reported also in Additional file 1: Table S3 and S4), were estimated up to $93 \%$ (Table 2).

The $\gamma$-ray spectrum obtained showed the $\gamma$-lines of terbium-155 together with those of terbium-156, terbium-154, terbium-154m and terbium-154m2 [Additional file 1: 


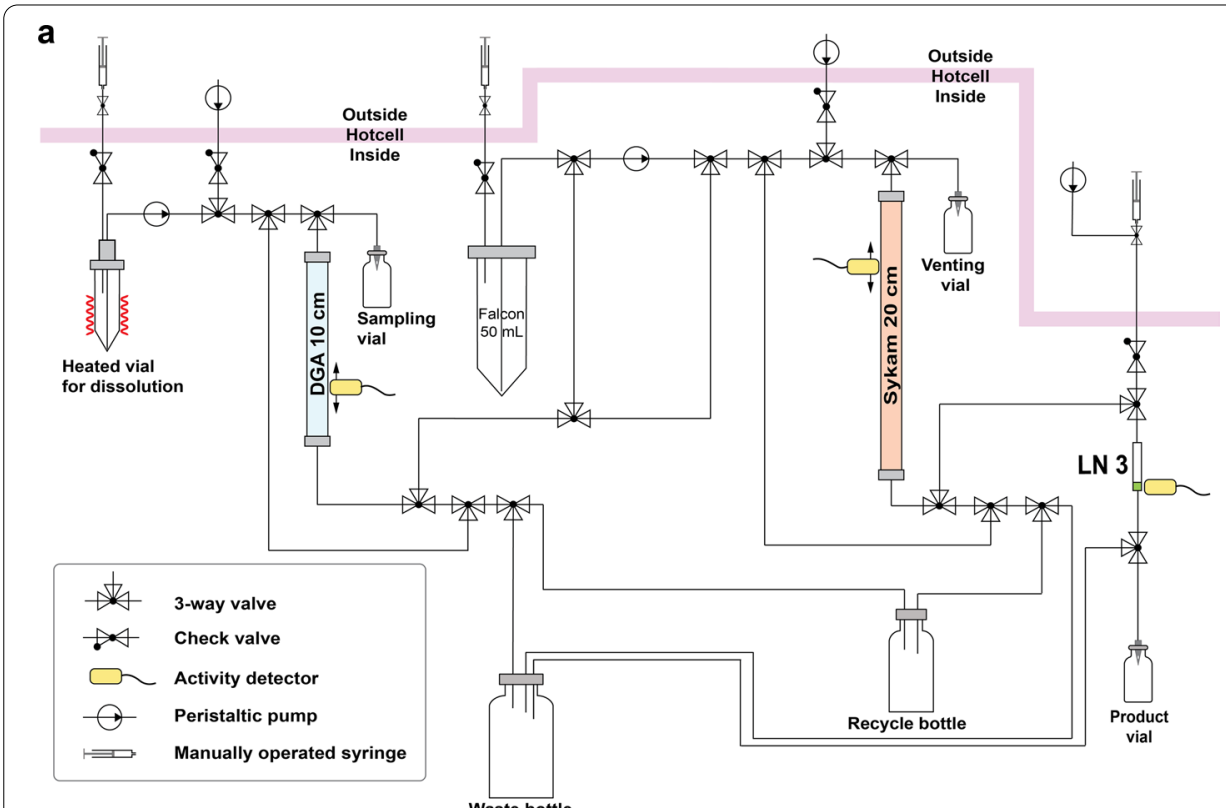

b

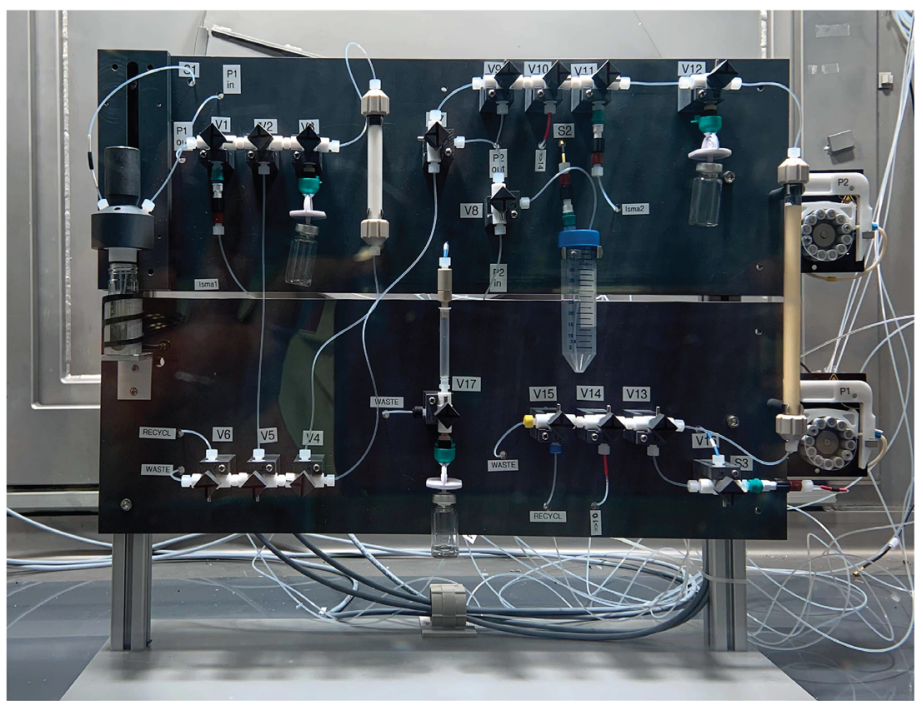

Fig. 5 Schematic diagram of the terbium-155 separation panel (a) and image of the actual system (b). (Blue, orange and white colors in the diagram represent the columns that contain DGA, Sykam and LN3 resins, respectively).

Table S5-S6 and Fig. S6, (Nica 2019; Reich 2009, Reich 2012)]. While terbium-156 has a half-life $\left(\mathrm{T}_{1 / 2}=5.3 \mathrm{~d}\right)$ similar to terbium-155, the other radionuclidic impurities terbium-154, terbium-154m and terbium-154m2 are short-lived terbium isotopes with 21 . $5 \mathrm{~h}, 9.4 \mathrm{~h}$ and $22.7 \mathrm{~h}$ half-lives, respectively [Additional file 1: Table S5, (Nica 2019; Reich 2009, Reich 2012)]. In particular, the measurements took place after each separation, approximately 2 days after EOB (Additional file 1: Table S6). 
Table 2 Selected terbium-155 production runs, indicating measured activity EOB and EOS for each run

\begin{tabular}{lllllll}
\hline $\begin{array}{l}\text { Production } \\
\text { No }\end{array}$ & Nuclear reaction & $\begin{array}{l}\text { Irradiation } \\
\text { time (h) }\end{array}$ & $\begin{array}{l}{\left[^{155} \mathrm{~Tb}\right] \mathrm{Tb}} \\
\text { EOB (MBq) }\end{array}$ & $\begin{array}{l}\left.{ }^{155} \mathrm{~Tb}\right] \mathrm{Tb} \\
\text { EOS (MBq) }\end{array}$ & $\begin{array}{l}{\left[^{155} \mathrm{~Tb}\right] \mathrm{Tb} \text { EOS (MBq) }} \\
\text { (corrected to EOB) }\end{array}$ & $\begin{array}{l}\text { Separation } \\
\text { yield (\%) }\end{array}$ \\
\hline 2 & ${ }^{155} \mathrm{Gd}(\mathrm{p}, \mathrm{n})^{155} \mathrm{~Tb}$ & 4 & 26.8 & 18.1 & 23.7 & 88.4 \\
5 & ${ }^{156} \mathrm{Gd}(\mathrm{p}, 2 \mathrm{n})^{155} \mathrm{~Tb}$ & 4 & 705 & 487 & 555 & 78.7 \\
7 & ${ }^{156} \mathrm{Gd}(\mathrm{p}, 2 \mathrm{n})^{155} \mathrm{~Tb}$ & 8 & 1250 & 829 & 1029 & 82.3 \\
8 & ${ }^{156} \mathrm{Gd}(\mathrm{p}, 2 \mathrm{n})^{155} \mathrm{~Tb}$ & 8 & 1684 & 1021 & 1279 & 75.9 \\
9 & ${ }^{156} \mathrm{Gd}(\mathrm{p}, 2 \mathrm{n})^{155} \mathrm{~Tb}$ & 8 & 900 & 668 & 836 & 92.9 \\
\hline
\end{tabular}

Productions 3 and 6 were excluded due to technical failures of the separation panel. To calculate the separation yield, the EOS activity was corrected to EOB time considering the decay correction (sixth column) and then used to calculate the fraction of initial activity recovered after the separation

Table 3 Quality control of terbium-155 after the radiochemical separation process (the molar activity of radiolabeled product)

\begin{tabular}{lllll}
\hline Production no & Nuclear reaction & $\begin{array}{l}\text { Irradiation time } \\
\text { (h) }\end{array}$ & $\begin{array}{l}\left.{ }^{[155} \mathrm{Tb}\right] \mathrm{Tb} \text { EOS } \\
\text { (MBq) }\end{array}$ & $\begin{array}{l}\text { >95\% radiolabeled } \\
\text { molar activity (MBq/ } \\
\text { nmol) }\end{array}$ \\
\hline 2 & ${ }^{155} \mathrm{Gd}(\mathrm{p}, \mathrm{n}){ }^{155} \mathrm{~Tb}$ & 4 & 18.1 & n.a \\
5 & ${ }^{156} \mathrm{Gd}(\mathrm{p}, 2 \mathrm{n}){ }^{155} \mathrm{~Tb}$ & 4 & 487 & 100 \\
7 & ${ }^{156} \mathrm{Gd}(\mathrm{p}, 2 \mathrm{n}){ }^{155} \mathrm{~Tb}$ & 8 & 829 & 100 \\
8 & ${ }^{156} \mathrm{Gd}(\mathrm{p}, 2 \mathrm{n}){ }^{155} \mathrm{~Tb}$ & 8 & 1021 & 100 \\
9 & ${ }^{156} \mathrm{Gd}(\mathrm{p}, 2 \mathrm{n}){ }^{155} \mathrm{~Tb}$ & 8 & 668 & 50 \\
\hline
\end{tabular}

\section{Radiolabeling yield}

Radiolabeling of DOTATOC with terbium-155 was reproducible at a molar activity of $50 \mathrm{MBq} / \mathrm{nmol}$, with $>99 \%$ radiochemical yield. Depending on the activity concentration of the $\left[{ }^{155} \mathrm{~Tb}\right] \mathrm{TbCl}_{3}$ solution, it was feasible to label at higher molar activities of up to $100 \mathrm{MBq} / \mathrm{nmol}$ with $>99 \%$ radiochemical purity (Table 3 and Additional file 1: Fig. S7). The LC-MS-ESI analysis of the radiolabeled samples with radiolabeling yield $<95 \%$ showed the presence of $\left[{ }^{155} \mathrm{~Tb}\right] \mathrm{Tb}$-DOTATOC together with Zn-DOTATOC and FeDOTATOC, while Gd-DOTATOC was not detected (Additional file 1: Fig. S8 for radiolabeling of production 9 at $100 \mathrm{MBq} / \mathrm{nmol}$ ).

\section{SPECT/CT imaging studies}

\section{Derenzo phantom}

Derenzo phantom studies performed with terbium-155 showed excellent spatial resolution and resolvable line widths up to $1.0 \mathrm{~mm}$ after $15 \mathrm{~min}$ scanning time (Fig. 6).

\section{In vivo studies}

In vivo imaging using $\left[{ }^{155} \mathrm{~Tb}\right] \mathrm{Tb}$-DOTATOC allowed excellent tumor visualization (Fig. 7). The ${ }^{155} \mathrm{~Tb}$-radiolabeled SST analogue accumulated in AR42J tumor already after $1 \mathrm{~h}$ p.i. The activity in the tumor was still high at $4 \mathrm{~h}$ p.i., while it decreased after $24 \mathrm{~h}$ p.i.. The renal retention of $\left[{ }^{155} \mathrm{~Tb}\right] \mathrm{Tb}$-DOTATOC was high shortly after injection, but the activity was cleared efficiently over time. 


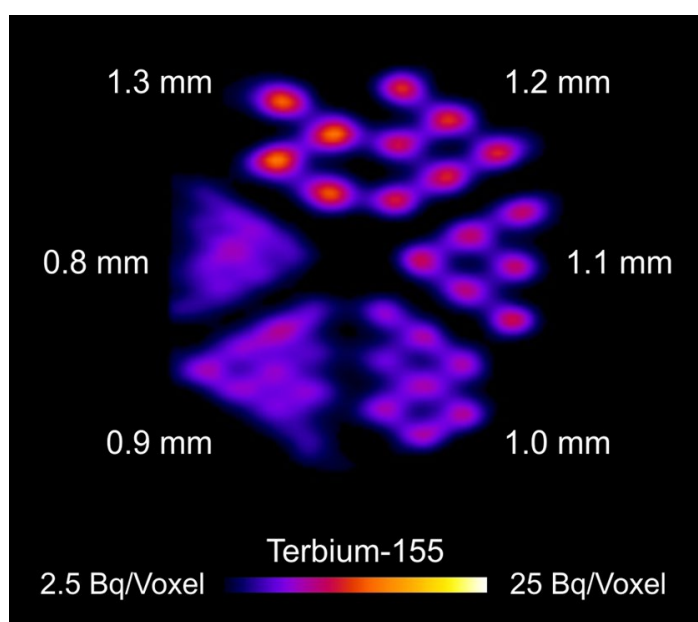

Fig. 6 Fifteen-minute SPECT scan of sagittal sections of Derenzo phantom filled with terbium-155 (10 MBq). No filter was applied.

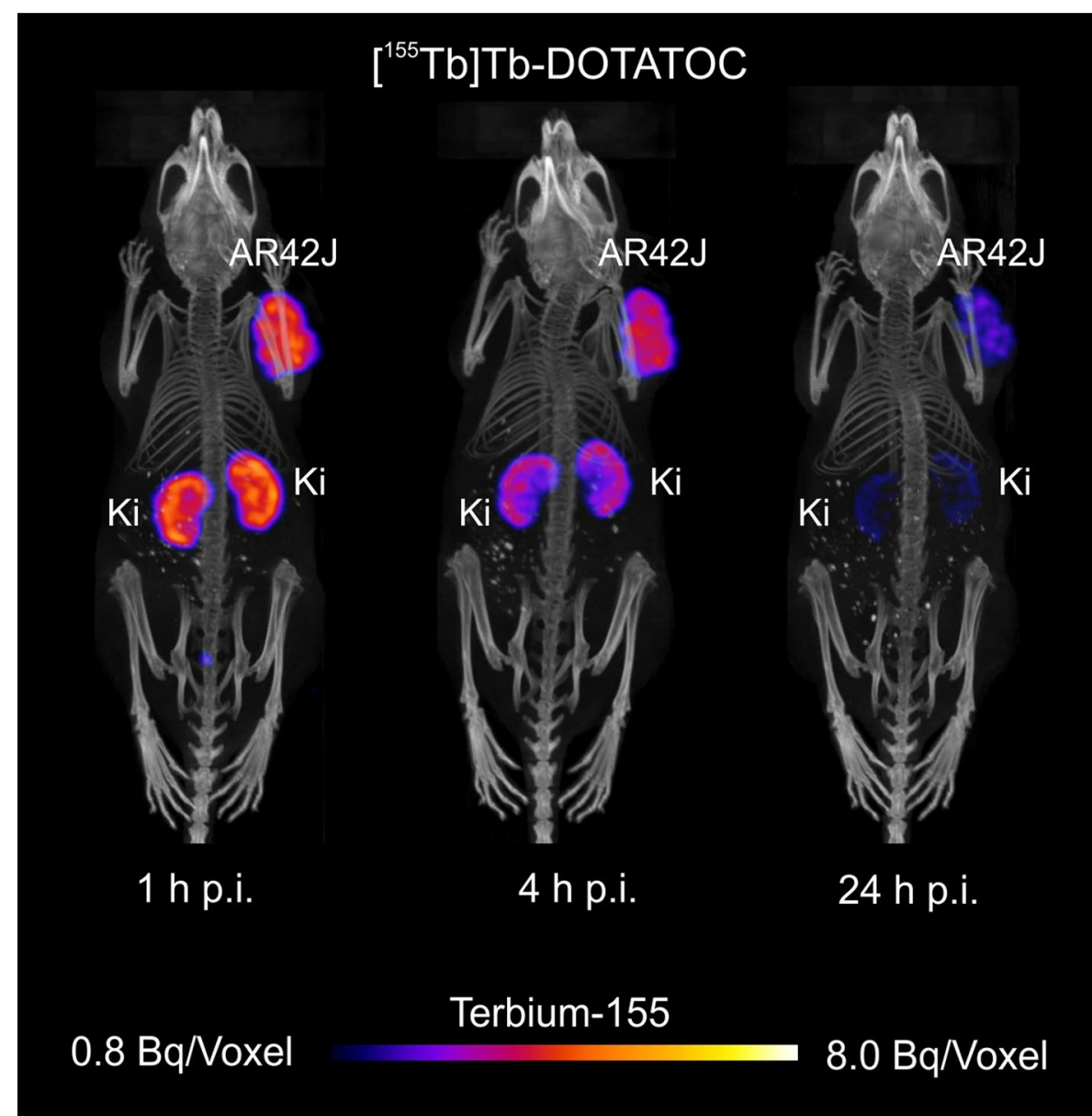

Fig. 7 In vivo SPECT/CT scans of AR42J tumor-bearing mouse injected with [ $\left.{ }^{155} \mathrm{~Tb}\right] \mathrm{Tb}-\mathrm{DOTATOC}$ (10 MBq, 1.0 $\mathrm{nmol} ; 100 \mu \mathrm{L})$. The scans were acquired 1,4 and $24 \mathrm{~h}$ pi. During the scans the mouse was anesthetized with a mixture of isoflurane and oxygen. (AR42J = SSTR-positive tumor xenograft, $\mathrm{Ki}=$ kidney). (Voxel size: $0.3 \mathrm{~mm}$ ) 


\section{Discussion}

In this study, the first reproducible production of GBq activities of terbium-155 via the ${ }^{155} \mathrm{Gd}(\mathrm{p}, \mathrm{n}){ }^{155} \mathrm{~Tb}$ and ${ }^{156} \mathrm{Gd}(\mathrm{p}, 2 \mathrm{n}){ }^{155} \mathrm{~Tb}$ nuclear reactions, to our knowledge, was performed. In contrast to previous studies in which the production of terbium-155 (in MBq activities) was performed by spallation followed by mass separation (Fiaccabrino et al. 2021; Müller et al. 2012, 2014a; Webster et al. 2019), the current study was able to demonstrate the possibility of producing terbium-155 activities in view of clinical application. The production via ${ }^{155} \mathrm{Gd}(\mathrm{p}, \mathrm{n}){ }^{155} \mathrm{~Tb}$ was carried out both at a research cyclotron and a medical cyclotron, while the ${ }^{156} \mathrm{Gd}(\mathrm{p}, 2 \mathrm{n}){ }^{155} \mathrm{~Tb}$ was achieved at a research cyclotron only, due to the higher beam energy required (it must be noted that this production route is possible with commercial cyclotrons that can produce $24 \mathrm{MeV}$ protons). The results obtained using a medical cyclotron represent a promising important step towards the implementation of terbium-155 production in quality and quantity suitable for application in nuclear medicine. However, as expected based on previously reported investigations, the ${ }^{156} \mathrm{Gd}(\mathrm{p}, 2 \mathrm{n})^{155} \mathrm{~Tb}$ nuclear reaction generated higher terbium-155 activities than the ${ }^{155} \mathrm{Gd}(\mathrm{p}, \mathrm{n}){ }^{155} \mathrm{~Tb}$ nuclear reaction (. 2021a; Dmitriev et al. 1989; Vermeulen et al. 2012). A note of caution may be due here since the production yields may not be optimal: the IP2 research beamline requires degrading of the proton beam and this would result in beam spread (van der Meulen et al. 2019, 2020a); however, the majority of the production yields were reproducible.

Furthermore, after the purification process, it was possible to obtain up to $1.0 \mathrm{GBq}$ of $\left[{ }^{155} \mathrm{~Tb}\right] \mathrm{TbCl}_{3}$ with a high level of chemical purity enabling labeling of biomolecules at up to $100 \mathrm{MBq} / \mathrm{nmol}$. When the radiolabeling at high molar activities failed, a correlation with a low activity concentration was observed, implying that at low terbium-155 activities it was easy for metal environmental contaminants, mainly $\mathrm{Zn}$ and Fe, to compete with terbium-155 for the free chelator sites of DOTATOC (Asti et al. 2012; Talip et al. 2021, 2020). This hypothesis was also confirmed by means of LC-MS-ESI analysis of the radiolabeled samples. At higher terbium-155 activities, the analysis attested that the purification process of terbium-155 from the target material developed in this work was successful and effective. In particular, the purification process consisted of a three-column procedure that guaranteed the separation of a very small amount of terbium (1.7 GBq terbium-155 corresponds to $\sim 1 \mu \mathrm{g}$ of terbium) from a massive amount of gadolinium (40 mg of target material). The current method represents an improved process with respect to time as well as product purity, compared to that previously reported by our group (Gracheva et al. 2019), due to the introduction of a third column and further purification steps. The use of the DGA extraction resin column spared a time-consuming evaporation step before loading the reduced quantity of target material, along with the desired product, onto the Sykam resin column. In the elution profile of the DGA column, a partial separation between terbium and gadolinium was observed, resulting in a 50\% reduction of gadolinium loaded onto the Sykam column, with a consequent higher separation efficiency and reproducibility. This implies the possibility of increasing the mass of target material to irradiate, which could allow for higher production yields. Another advantage of the revised method is that the final column, containing LN3 extraction resin, was used as a last purification step in where any remaining traces of gadolinium could be removed with $0.01 \mathrm{M} \mathrm{HCl}$ before final elution of terbium-155. 
The separation yield resulted in $75-90 \%$, indicating that only $10-25 \%$ of terbium- 155 activity were lost during separation, predominantly on the DGA resin column and final rinsing steps.

In contrast to the mass-separated terbium-155, the product in the present study (from both nuclear reactions) was obtained together with terbium-154, terbium-154m, terbium-154m2 and terbium-156. The radionuclidic purity was demonstrated to be dependent on the nuclear reaction used for terbium-155 production. In particular, when the ${ }^{156} \mathrm{Gd}(\mathrm{p}, 2 \mathrm{n}){ }^{155} \mathrm{~Tb}$ nuclear reaction was induced, the fraction of terbium-156 was measured as $\sim 8 \%$ at EOS, which decreased to $\sim 6 \%$ when the ${ }^{155} \mathrm{Gd}(\mathrm{p}, \mathrm{n}){ }^{155} \mathrm{~Tb}$ reaction was utilized. The longer-lived radionuclidic impurity terbium-156 has an almost identical half-life to the radioisotope of interest (Additional file 1: Table S5), making it impossible to be removed from the final product by decay. The 154 isobars are, however, short-lived radionuclidic impurities $\left[\mathrm{T}_{1 / 2}<23 \mathrm{~h}\right.$ (Reich 2009)], implying that the impurity could be eliminated after less than one week of decay. In future, the option of purifying the final product using an off-line mass separation technique could be evaluated (Talip et al. 2021) to separate terbium-156 from terbium-155, in order to increase the radionuclidic purity, even though this approach would inevitably reduce the final production yields due to the currently poor efficiency of ionization. To develop a full picture of the topic, additional studies will be needed to include the dosimetry of terbium-156 in a hypothetical clinical setting, in order to establish the right compromise between production outcome and radiological safety.

Furthermore, in this work, a Derenzo Phantom SPECT study was performed with terbium-155, which was comparable to that previously obtained with the mass-separated terbium-155 and approximately same collected counts (Müller et al. 2014a), meaning that the presence of other terbium radioisotopes appeared not to affect the visual resolution of the picture. Moreover, preliminary cell experiments confirmed that the behavior of $\left[{ }^{155} \mathrm{~Tb}\right] \mathrm{Tb}$-DOTATOC was comparable to that of the previously reported for its ${ }^{177} \mathrm{Lu}$ radiolabeled counterpart (Additional file 1: Fig S10) (Borgna et al. 2021), and allowed further in vivo studies. Importantly, the SPECT/CT in vivo imaging study, using the mentioned radiolabeled SST analogue, demonstrated the applicability of cyclotron-produced terbium-155 for imaging purposes along with its excellent feature for visualization of the accumulated radiolabeled compound in the tumors. In particular, the in vivo distribution was comparable with that of the same ${ }^{177} \mathrm{Lu}$ - or ${ }^{161} \mathrm{~Tb}$-labeled biomolecule previously performed (Borgna et al. 2021). As a result, terbium-155 could play an important role towards the application of radiotheragnostics in the field.

\section{Conclusions}

In the present study, it was demonstrated that high activities of terbium-155 can be produced via proton irradiation of highly enriched gadolinium-155 or gadolinium-156 oxide targets. The ${ }^{156} \mathrm{Gd}(\mathrm{p}, 2 \mathrm{n})^{155} \mathrm{~Tb}$ nuclear reaction demonstrated higher production yields, however, lower radionuclidic purity in comparison with the final product of the ${ }^{155} \mathrm{Gd}(\mathrm{p}, \mathrm{n})^{155} \mathrm{~Tb}$ nuclear reaction was observed. As the latter method would be feasible on a medical cyclotron and, thus, more likely to be used in future, it remains to be determined as to how these co-produced terbium radioisotopes can affect patients from a dosimetry perspective. The high chemical purity of the final 
separated product $\left(\left[{ }^{155} \mathrm{~Tb}\right] \mathrm{TbCl}_{3}\right)$, ensured radiolabeling of tumor targeting molecules, which would be necessary for clinical application. The results of this research support the idea that cyclotron-produced terbium-155 is a promising radionuclide for medical purposes and lay the groundwork for further preclinical in vitro and in vivo investigations, together with future potential clinical applications.

\begin{abstract}
Abbreviations
SPECT: Single photon emission computed tomography; EOB: End of bombardment; BTL: Beam transfer line; STS: Solid target station; STTS: Solid target transfer system; CZT: CdZnTe crystal; LHEP: Laboratory of high energy physics; EOS: End of separation; DGA: N,N,N',N'-tetra-n-octyldiglycolamide extraction resin; LN3: Bis(2,4,4-trimethyl-1-pentyl) phosphinic acid extraction resin; a-HIBA: a-Hydroxy-isobutyric acid; HPGe: High-purity Germanium; HPLC: High performance liquid chromatography; LC-MS-ESI: Liquid chromatography-mass spectrometry-electrospray ionization; DTPA: Diethylenetriamine pentaacetic acid; SST: Somatostatin.
\end{abstract}

\title{
Supplementary Information
}

The online version contains supplementary material available at https://doi.org/10.1186/s41181-021-00153-w.

Additional file 1. Supplementary Material.

\section{Acknowledgements}

The authors thank PSI's Radionuclide_-Production and Maintenance Group (Roger Geissmann, Muhamet Djelili), Fan Sozzi-Guo, Alain Blanc and Roman Küng for technical support and assistance.

\section{Authors' contributions}

CF developed the production and separation process, performed the bench experiments, the separation experiments with terbium-155, the quality controls on the product, the in vitro and in vivo studies, and analyzed the data and drafted the manuscript. ZT designed, supervised and supported the development of the production and the chemical separation process and revised the manuscript. PVG supported the chemical separation process and revised the manuscript. FB supported the in vitro and in vivo studies and revised the manuscript, while CM was responsible and for the performance of those studies and revised the manuscript. $\mathrm{HZ}$ revised the manuscript and were responsible for the irradiations of gadolinium targets performed at PSI's Injector. AS supported the irradiations performed at PSI's Injector 2. SB was responsible for the irradiations at the Bern medical cyclotron. GD performed the irradiations at the Bern medical cyclotron and analyzed the data. GD, together with SB, wrote the parts concerning the Bern medical cyclotron and revised the manuscript. RS reviewed the manuscript. NvdM was responsible for the development of the production and separation process of terbium-155, organized and supervised the whole study, revised and finalized the manuscript. All authors read and approved the final manuscript.

\section{Funding}

The research was funded by the Swiss National Science Foundation (SNSF) (Grants: 200021_188495 and CRSIII_180352). Dr. Francesca Borgna received funding from the European Union's Horizon 2020 research and innovation program under the Marie Skłodowska-Curie Grant Agreement No. 701647 and from the Swiss Cancer Research Foundation, Grant No. KFS-4678-02-2019-R (PI: Cristina Müller).

Availability of data and materials

The dataset(s) supporting the conclusions of this article is (are) included within the article (and its additional file(s)).

\section{Declarations}

Ethics approval and consent to participate

This article does not contain any studies with human participants performed by any of the authors. All the applicable international, national, and/or institutional guidelines for the care and use of animals were followed.

\section{Consent for publication}

Not applicable.

\section{Competing interests}

The authors declare that they have no competing interests.

\section{Author details}

${ }^{1}$ Center for Radiopharmaceutical Sciences, ETH-PSI-USZ, Paul Scherrer Institute, 5232 Villigen-PSI, Switzerland. ${ }^{2}$ Albert Einstein Center for Fundamental Physics (AEC), Laboratory of High Energy Physics (LHEP), University of Bern, 3012 Bern, Switzerland. ${ }^{3}$ Division Large Research Facilities, Paul Scherrer Institute, 5232 Villigen-PSI, Switzerland. ${ }^{4}$ Department of Chemistry and Applied Biosciences, ETH Zurich, 8093 Zurich, Switzerland. ${ }^{5}$ Laboratory of Radiochemistry, Paul Scherrer Institute, 5232 Villigen-PSI, Switzerland. 
Received: 5 August 2021 Accepted: 26 October 2021

Published online: 14 November 2021

\section{References}

Asti M, Tegoni M, Farioli D, lori M, Guidotti C, Cutler CS, et al. Influence of cations on the complexation yield of DOTATATE with yttrium and lutetium : a perspective study for enhancing the ${ }^{90} \mathrm{Y}$ and ${ }^{177} \mathrm{Lu}$ labeling conditions. Nucl Med Biol. 2012;39(4):509-17.

Baum RP, Singh A, Kulkarni HR, Bernhardt P, Rydén T, Schuchardt C, et al. First-in-human application of terbium-161: a feasibility study using ${ }^{161}$ Tb-DOTATOC. J. Nucl. Med. 2021;1-25.

Blachot J. Nuclear Data Sheets for A = 111. Nucl Data Sheets. 2009;110(6):1239-407

Borgna F, Barritt P, Grundler PV, Talip Z, Cohrs S, Zeevaart JR, et al. Simultaneous visualization of ${ }^{161}$ Tb-and ${ }^{177}$ Lu-Labeled somatostatin analogues using dual-isotope SPECT imaging. Pharmaceutics. 2021;13(4):1-13.

Braccini S. The new bern PET cyclotron, its research beam line, and the development of an innovative beam monitor detector. AIP Conf. Proc. 2013. p. 144-50.

Braccini S, Belver Aguilar C, Carzaniga TS, Dellepiane G, Häffner PD, Scampoli P, Novel irradiation methods for theranostic radioisotope production with solid targets at the Bern medical cyclotron. In: CYC 2019 - Proc. 22nd Int. Conf. Cyclotrons their Appl. 2020. p. 128-32.

Browne E, Tuli JK. Nuclear data sheets for A = 99. Nucl Data Sheets. 2017;145:25-340.

Buck AK, Nekolla S, Ziegler S, Beer A, Krause BJ, Herrmann K, et al. SPECT/CT. J Nucl Med. 2008;49(8):1305-19.

Bunka M, Müller C, Vermeulen C, Haller S, Türler A, Schibli R, et al. Imaging quality of ${ }^{44} \mathrm{SC}$ in comparison with five other PET radionuclides using Derenzo phantoms and preclinical PET. Appl Radiat Isot. 2016;110:129-33.

Camera L, Kinuya S, Garmestani K, Brechbiel MW, Wu C, Pai LH, et al. Comparative biodistribution of indium- and yttriumlabeled B3 monoclonal antibody conjugated to either 2-(p-SCN-Bz)-6-methyl-DTPA (1 B4M-DTPA) or 2-(p-SCN-Bz)1,4,7,10-tetraazacyclododecane tetraacetic acid (2B-DOTA). Eur J Nucl Med. 1994;21(7):640-6.

Dellepiane G, Casolaro P, Haffner PD, Mateu I, Scampoli P, Voeten N, et al. Instruments and methods for theranostic radioisotope production at the Bern medical cyclotron. TIPP2020 - Int. Conf. Technol. Instrum. Part. Phys. 2021.

Dellepiane G et al. In preparation. Appl. Radiat. Isot. 2022.

Dmitriev PP, Molin GA, Dmitrieva ZP. Production of 155Tb for nuclear medicine in the reactions 155Gd(p, n), 156Gd(p,2n), and 155Gd(d,2n). At Ehnergiya. 1989;66(6):419-21.

Domnanich KA, Müller C, Benešová M, Dressler R, Haller S, Köster U, et al. ${ }^{47}$ Sc as useful $\beta$-emitter for the radiotheragnostic paradigm: a comparative study of feasible production routes. EJNMMI Radiopharm Chem. 2016;2(1):1-17.

Durán MT, Juget F, Nedjadi Y, Bochud F, Grundler PV, Gracheva N, et al. Determination of ${ }^{161} \mathrm{~Tb}$ half-life by three measurement methods. Appl Radiat Isot. 2020;159(109085):1-9.

Favaretto C, Talip Z, Grundler P, Geistlich S, Landolt S, Schmid D, et al. The production of ${ }^{161} \mathrm{~Tb}$ and its introduction to the clinic through the Good Manufacturing Practice-compliant radiolabeling of [ $\left.{ }^{161} \mathrm{~Tb}\right] \mathrm{Tb}-\mathrm{DOTATOC}$. Nucl Med Biol. 2021;2021(96-97):S62-3.

Fiaccabrino DE, Kunz P, Radchenko V. Potential for production of medical radionuclides with on-line isotope separation at the ISAC facility at TRIUMF and particular discussion of the examples of ${ }^{165} \mathrm{Er}$ and ${ }^{155} \mathrm{~Tb}$. Nucl Med Biol. 2021;94-95:81-91.

Gracheva N, Müller C, Talip Z, Heinitz S, Köster U, Zeevaart JR, et al. Production and characterization of no-carrieradded ${ }^{161} \mathrm{~Tb}$ as an alternative to the clinically-applied ${ }^{177}$ Lu for radionuclide therapy. EJNMMI Radiopharm Chem. 2019;4(12):1-16.

Grundler PV, Eichler R, Talip Z, Schubiger PA, Schibli R, van der Meulen NP. The metamorphosis of radionuclide production and development at paul scherrer institute. Chimia (aarau). 2020;74(12):968-75.

Lee WW. Clinical applications of technetium-99m quantitative single-photon emission computed tomography/computed tomography. Nucl Med Mol Imaging. 2019;53:172-81.

Mariani G, Bruselli L, Kuwert T, Kim EE, Flotats A, Israel O, et al. A review on the clinical uses of SPECT/CT. Eur J Nucl Med Mol Imaging. 2010;37(10):1959-85.

Müller C, Zhernosekov K, Koster U, Johnston K, Dorrer H, Hohn A, et al. A unique matched quadruplet of terbium radioisotopes for PET and SPECT and for $\alpha$ - and $\beta$-radionuclide therapy: an in vivo proof-of-concept study with a new receptor-targeted folate derivative. J Nucl Med. 2012;53(12):1951-9.

Müller C, Umbricht CA, Gracheva N, Tschan VJ, Pellegrini G, Bernhardt P, et al. Terbium-161 for PSMA-targeted radionuclide therapy of prostate cancer. Eur J Nucl Med Mol Imaging. 2019;46(9):1919-30.

Müller C, Fischer E, Behe M, Köster U, Dorrer H, Reber J, et al. Future prospects for SPECT imaging using the radiolanthanide terbium-155_-production and preclinical evaluation in tumor-bearing mice. Nucl Med Biol. 2014a;41(S):58-65.

Müller C, Reber J, Haller S, Dorrer H, Bernhardt P, Zhernosekov K, et al. Direct in vitro and in vivo comparison of ${ }^{161} \mathrm{~Tb}$ and

${ }^{177}$ Lu using a tumour-targeting folate conjugate. Eur J Nucl Med Mol Imaging. 2014b;41(3):476-85.

Nica N. Nuclear data sheets for $A=155$. Nucl Data Sheets. 2019;160:1-404.

Reich CW. Nuclear data sheets for $A=154$. Nucl Data Sheets. 2009:110(10):2257-532

Reich CW. Nuclear data sheets for $A=156$. Nucl Data Sheets. 2012;113(11):2537-840

Rösch F, Herzog H, Qaim SM. The beginning and development of the theranostic approach in nuclear medicine, as exemplified by the radionuclide pair ${ }^{86} Y$ and ${ }^{90} Y$. Pharmaceuticals. 2017;10(2):1-28.

Talip Z, Favaretto C, Geistlich S, Van Der Meulen NP. A step-by-step guide for the novel radiometal production for medical applications: Case studies with ${ }^{68} \mathrm{Ga},{ }^{44} \mathrm{SC},{ }^{177}$ Lu and ${ }^{161} \mathrm{~Tb}$. Molecules. 2020;25(966):1-28.

Talip Z, Borgna F, Müller C, Ulrich J, Duchemin C, Ramos JP, et al. Production of Mass-Separated Erbium-169 Towards the First Preclinical in vitro Investigations. Front Med. 2021;8(April):1-11.

Umbricht CA, Köster U, Bernhardt P, Gracheva N, Johnston K, Schibli R, et al. Alpha-PET for Prostate Cancer: Preclinical investigation using ${ }^{149}$ Tb-PSMA-617. Sci Rep. 2019;9(1):1-10. 
van der Meulen NP, Bunka M, Domnanich KA, Müller C, Haller S, Vermeulen C, et al. Cyclotron production of ${ }^{44}$ Sc: from bench to bedside. Nucl Med Biol. 2015;42(9):745-51.

van der Meulen NP, Hasler R, Blanc A, Farkas R, Benešová M, Talip Z, et al. Implementation of a new separation method to produce qualitatively improved ${ }^{64} \mathrm{Cu}$. J Label Compd Radiopharm. 2019b;62(8):460-70.

van der Meulen NP, Eichler R, Grundler P V., Hasler R, Hirzel W, Joray S, et al. The use of PSI's IP2 beam line towards exotic radionuclide development and its application towards proof-of-principle preclinical and clinical studies. CYC 2019 Proc. 22nd Int. Conf. Cyclotrons their Appl. 2020a;:133-6.

van der Meulen NP, Hasler R, Talip Z, Grundler PV, Favaretto C, Umbricht CA, et al. Developments toward the implementation of ${ }^{44}$ Sc production at a medical cyclotron. Molecules. 2020b;25(4706):1-16.

Vermeulen C, Steyn GF, Szelecsényi F, Kovács Z, Suzuki K, Nagatsu K, et al. Cross sections of proton-induced reactions on ${ }^{n a t} \mathrm{Gd}$ with special emphasis on the production possibilities of ${ }^{152} \mathrm{~Tb}$ and ${ }^{155} \mathrm{~Tb}$. Nucl. Instruments Methods Phys. Res. Sect. B Beam Interact. Mater. Atoms. 2012;275:24-32.

Weber WA, Czernin J, Anderson CJ, Badawi RD, Barthel H, Bengel F, et al. The Future of Nuclear Medicine, Molecular Imaging, and Theranostics. J Nucl Med. 2020;61:263S-272S

Webster B, Ivanov P, Russell B, Collins S, Stora T, Ramos JP, et al. Chemical Purification of Terbium-155 from Pseudo-Isobaric Impurities in a Mass Separated Source Produced at CERN. Sci Rep. 2019;9(1):1-9.

Witzig TE. Radioimmunotherapy for patients with relapsed B-cell non-Hodgkin lymphoma. Cancer Chemother Pharmacol. 2001:48(SUPPL. 1):91-5.

Ziegler JF, Ziegler MD, Biersack JP. SRIM — The stopping and range of ions in matter. Nucl. Instruments Methods Phys. Res. Sect. B Beam Interact. Mater. Atoms. 2010;268(11-12):1818-23.

\section{Publisher's Note}

Springer Nature remains neutral with regard to jurisdictional claims in published maps and institutional affiliations.

\section{Submit your manuscript to a SpringerOpen ${ }^{\circ}$ journal and benefit from:}

- Convenient online submission

- Rigorous peer review

- Open access: articles freely available online

- High visibility within the field

Retaining the copyright to your article

Submit your next manuscript at $\boldsymbol{\Delta}$ springeropen.com 